\title{
ON THE INFLUENCES OF MAIN ENGINE PARAMETERS ON EEDI EVALUATION FOR A BULK CARRIER
}

\author{
Alexandra I. Diaconița \\ NASDIS Consulting SRL, \\ 6, Tecuci Street, Bl.V5, Et. 1, Galați, \\ 800120, România, \\ E-mail: alexandra.diaconita@nasdis.ro
}

\author{
Liviu Crudu \\ "Dunărea de Jos" University of Galaţi, \\ Faculty of Naval Architecture, \\ 47, Domnească Street, 800008, România, \\ E-mail: liviu.crudu@ugal.ro
}

\begin{abstract}
The objective of this study is to evaluate the influence of the different characteristics of some types of engines on the propulsion performances from the economic point of view and the impact on the Energy Efficiency Design Index (EEDI) and the Energy Efficiency Operational Indicator (EEOI). The analysis was carried out for different solutions of motorization. The preliminary design of the propeller was performed taking into account two values of the diameter according to design procedures. For each diameter two engines were selected in order to have a comparative analysis.

It is well known that IMO has adopted strict regulations related to the emission of air pollutants from ships and mandatory energy-efficiency measures to reduce emissions of greenhouse gases under Annex VI of IMO's pollution prevention treaty (MARPOL). IMO has established a series of baselines regarding the amount of fuel to be burned by each type of ship for a certain cargo capacity [1]. Ships to be built in the near future have to comply with the provisions set up by baselines which will be progressively higher over time.
\end{abstract}

Keywords: Powering, Energy Efficiency Design Index, Energy Efficiency Operational Indicator, Ship propulsion, Ship resistance.

\section{INTRODUCTION}

Reducing the greenhouse gas (GHG) emissions became a key problem in order to avoid the most catastrophic impacts on climate changes.

Around $3 \%$ of the global $\mathrm{CO}_{2}$ emission is generated by ships. Three ship types are responsible of $55 \%$ of the total shipping $\mathrm{CO}_{2}$ emissions i.e. container ships $(23 \%)$, bulk carriers $(19 \%)$, and oil tankers (13\%), as shown in Figure 1[4].

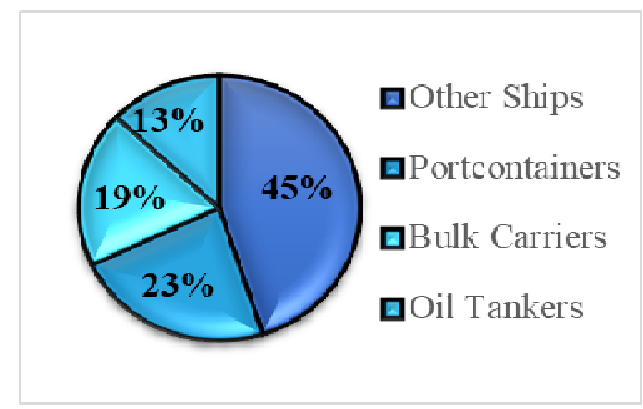

Fig. 1. Shipping GHG emissions 
Generally, during the initial design stages, the main calculations are concentrated on the evaluation of ship resistance and propulsion in calm water, known as powering calculations. There are three important factors which are continuously demanding new ways to approach the preliminary stages known as Front - End - Engineering - Design (FEED): market globalization, modernization of harbour infrastructures and IMO new requirement related to pollution. Consequently, due to the significantly improvement of the operational time of goods in the harbours (port containers are the most relevant example) higher ship speeds are required leading to the necessity to design new modern ship forms, new propulsion solutions, new devices to improve the flow around the ship, better economical performances, etc. Taking also into account that, during her lifetime, the ship is operating in rough seas some additional power is required compared to the calm water case, keeping the operational indexes (motions and accelerations) below the required limits. Added resistance in waves, aerodynamic resistance, the sea state level, ship heading, etc. have to be more accurately considered in order to reach the desired performances requested by the owner. An application of a "sea margin" coefficient, between 10\%-20\% on the total required engine power, depending on ship type and operating area, is typically used.

The analysis has been carried out for a bulk carrier, having the following main characteristics:

Table 1. Main characteristics of the ship Length over all, $\mathrm{L}_{\mathrm{OA}} \quad 230.05 \quad$ [m] Length between $\quad 216.50 \quad$ [m] perpendiculars, $\mathrm{L}_{\mathrm{BP}}$ Length of waterline, $\mathrm{L}_{\mathrm{WL}} \quad 223.84 \quad$ [m] Breadth, B

$32.20 \quad[\mathrm{~m}]$

Depth, D

Draught, $\mathrm{T}$

Deadweight, $\mathrm{D}_{\mathrm{WT}}$

Design speed, v

$18.00 \quad[\mathrm{~m}]$

$14.40 \quad[\mathrm{~m}]$

72000 [dwt]

14.5 [Knot]

\section{SHIP RESISTANCE IN CALM WATER}

In order to evaluate ship resistance four different methods were used. The analysis has been performed for a range 6 of speeds between 12.5 knots and 16.5 knots with a step of 1 knot. The results are presented in Table 2 and Figure 2, respectively.

Table 1. Evaluation of ship resistance using 4 different methods [3]

\begin{tabular}{|c|c|}
\hline \multicolumn{2}{|c|}{ Holtrop-Mennen } \\
\hline $\mathbf{R}_{\mathbf{T}}[\mathbf{k N}]$ & Ship speed [Knot] \\
\hline 574.51 & 12.5 \\
\hline 679.13 & 13.5 \\
\hline 806.55 & 14.5 \\
\hline 957.96 & 15.5 \\
\hline 1148.87 & 16.5 \\
\hline \multicolumn{2}{|c|}{ Taylor-Gertler } \\
\hline $\mathbf{R}_{\mathrm{T}}[\mathbf{k N}]$ & Ship speed [Knot] \\
\hline 545.51 & 12.5 \\
\hline 686.94 & 13.5 \\
\hline 821.77 & 14.5 \\
\hline 969.94 & 15.5 \\
\hline 1180.19 & 16.5 \\
\hline \multicolumn{2}{|c|}{ Guldhammer - Harvald } \\
\hline $\mathbf{R}_{\mathrm{T}}[\mathbf{k N}]$ & Ship speed [Knot] \\
\hline 598.15 & 12.5 \\
\hline 709.30 & 13.5 \\
\hline 885.55 & 14.5 \\
\hline 1086.45 & 15.5 \\
\hline 1292.18 & 16.5 \\
\hline \multicolumn{2}{|c|}{ Japanese series } \\
\hline $\mathbf{R}_{\mathrm{T}}[\mathbf{k N}]$ & Ship speed [Knot] \\
\hline 650.86 & 12.5 \\
\hline 753.63 & 13.5 \\
\hline 874.92 & 14.5 \\
\hline 1021.19 & 15.5 \\
\hline 1214.15 & 16.5 \\
\hline
\end{tabular}

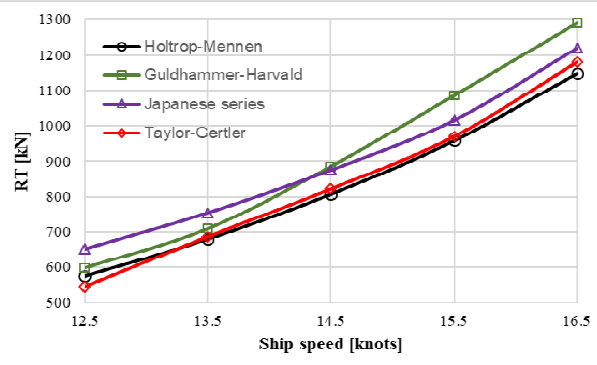

Fig. 2. Ship resistance calculations comparative results 
The Figure 2 shows that Holtrop Mennen method and the Taylor - Gertler one have close values while the Guldhammer Harvald and the Japanese series ones are overestimating ship's resistance. This could be a first dilemma in choosing the right method as far as there are quite significant differences between the two groups of methods. To carry out experimental model tests or, at least to perform CFD calculations using most reliable codes, have to be considered [3]. Being widely used, based on a large database, Holtrop-Mennen results will be considered latter.

\section{CALCULATION OF THE} ENERGY EFFICIENCY DESIGN INDEX (EEDI)

Practically, EEDI expresses the impact on the environment from shipping versus the benefit to society from shipping [3].

$$
\begin{aligned}
& E E D I=\frac{\text { Impact on environment }}{\text { Benefit to society }}
\end{aligned}
$$

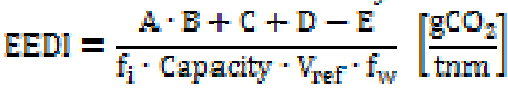

$$
\begin{aligned}
& A=\left(\prod_{i=1}^{M} f j\right) \\
& \mathrm{B}=\left(\sum_{\mathrm{i}=2}^{\mathrm{MME}} \mathrm{BuE}_{\mathrm{M}(\mathrm{i})} \cdot \mathrm{C}_{\mathrm{FME}(\mathrm{i})} \cdot \mathrm{SFC}_{\mathrm{ME}(\mathrm{i})}\right) \\
& \mathrm{C}=\left(\mathrm{P}_{\mathrm{AE}} \cdot \mathrm{C}_{\mathrm{FAE}} \cdot \mathrm{SFC}_{\mathrm{AE}}^{*}\right)
\end{aligned}
$$

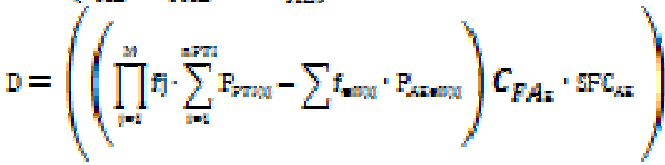

$$
\begin{aligned}
& \mathrm{E}=\left(\sum_{\mathrm{i}=1}^{\mathrm{neff}} \mathrm{f}_{\mathrm{effi}}-\mathrm{P}_{\mathrm{affi}} \cdot \mathrm{C}_{\mathrm{FME}}-S \mathrm{FC}\right. \text { ME } \\
& \mathrm{P}_{\mathrm{AE}}=2,5 \% P+250[\mathrm{~kW}]
\end{aligned}
$$

The notations used from A to E [3]:

- A, B represents the $\mathrm{CO}_{2}$ emissions from the main engine;

- $\mathrm{C}, \mathrm{D}$ represents the $\mathrm{CO}_{2}$ emissions from auxiliary engines;
- $E$ represents the reductions of $\mathrm{CO}_{2}$ emissions due to innovative technologies.

$>$ EEDI using design speed:

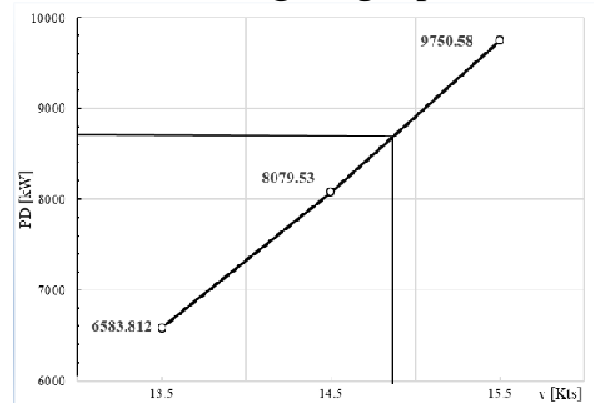

Fig. 3. Speed recalculated based on available propeller power and reference speed for

MAN B\&W S60ME-C8

Table 2. Calculation of the EEDI for MAN B\&W S60ME-C8 eingine

\begin{tabular}{|c|c|c|}
\hline Parameters & Values & Units \\
\hline $\mathbf{P}$ & 8925.0 & {$[\mathrm{~kW}]$} \\
\hline $\mathbf{P}_{\mathrm{AE}}$ & 547.5 & {$[\mathrm{~kW}]$} \\
\hline $\mathrm{V}_{\mathrm{ref}}$ & 14.85 & {$[\mathrm{Knots}]$} \\
\hline Attained EDDI & 4.56 & {$\left[\frac{g \mathrm{Co}_{2}}{\operatorname{tnm}}\right]$} \\
\hline
\end{tabular}
Required EDDI

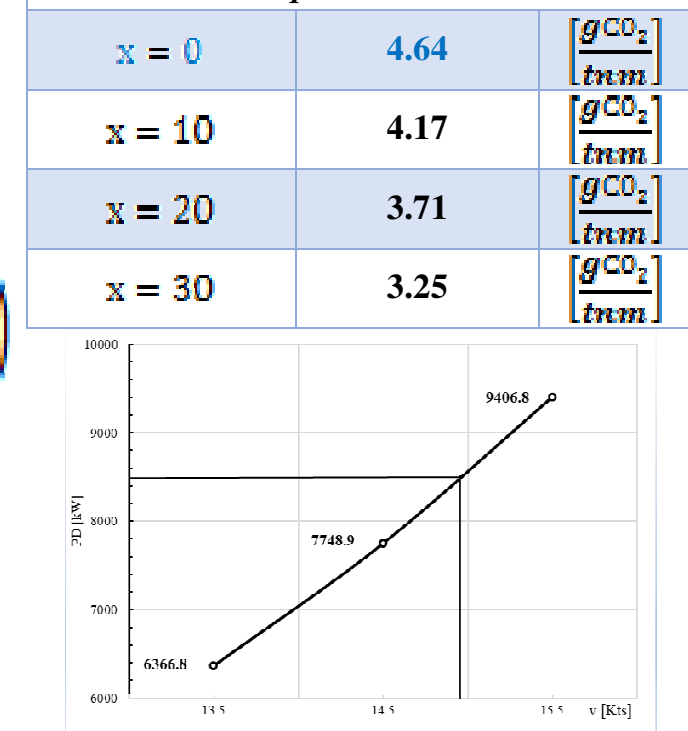

Fig. 4. Speed recalculated based on available propeller power and reference speed for MAN B\&W L42MC 
Table 3. Calculation of the EEDI for MAN B\&W S60ME-C8 engine

\begin{tabular}{|c|c|c|}
\hline Parameters & Values & Units \\
\hline $\mathrm{P}_{\mathrm{MF}}$ & 8955.0 & {$[\mathrm{~kW}]$} \\
\hline$P_{\mathrm{AE}}$ & 548.5 & {$[\mathrm{~kW}]$} \\
\hline$V_{\text {ref }}$ & 14.9 & [Knots] \\
\hline Attained EDDI & 4.77 & {$\left[\frac{g \mathrm{CO}_{2}}{\operatorname{trm}}\right]$} \\
\hline \multicolumn{3}{|c|}{ Required EDDI } \\
\hline$x=0$ & 4.64 & {$\left[\frac{g \mathrm{CO}_{2}}{\operatorname{trm}}\right]$} \\
\hline$x=10$ & 4.17 & {$\left[\frac{g \mathrm{CO}_{2}}{\mathrm{tm}}\right]$} \\
\hline$x=20$ & 3.71 & {$\left[\frac{g \mathrm{CO}_{2}}{\operatorname{trm}}\right]$} \\
\hline$x=30$ & 3.25 & {$\left[\frac{g \mathrm{Co}_{2}}{\operatorname{trm}}\right]$} \\
\hline
\end{tabular}

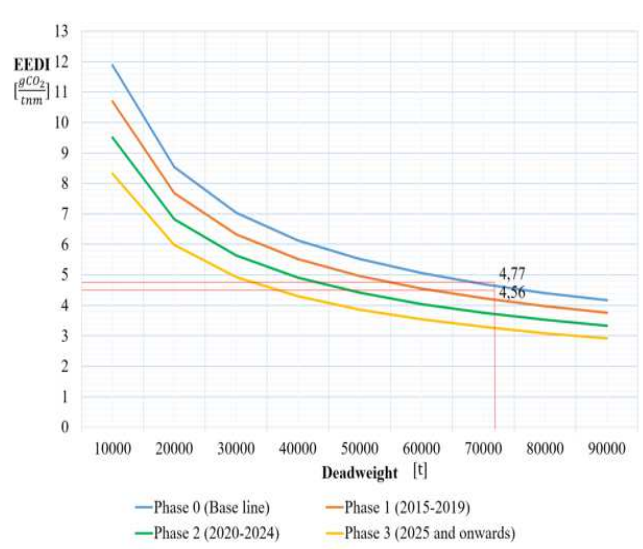

Fig. 5. Energy Efficiency Design Index using design speed

For the engine MAN B\&W S60ME-C8 the value of the attained EEDI falls below the reference line of Phase 0 , while for the engine MAN B\&W L42MC the attained EEDI value is above the reference line.

For 2015-2019 the value of attained $\left[\frac{\mathrm{gCO}_{2}}{\mathrm{tmm}}\right]$

EEDI should be $4.17\left[\frac{\overline{t r m}}{\text { trm }}\right]$. Both engines have higher EEDI values which place them above this reference line. In this case it becomes compulsory to find solutions to reduce EEDI.
$>$ EEDI $\mathrm{D}_{\mathrm{e}}=0,395 \cdot 14,4+1,3 \quad[5]:$

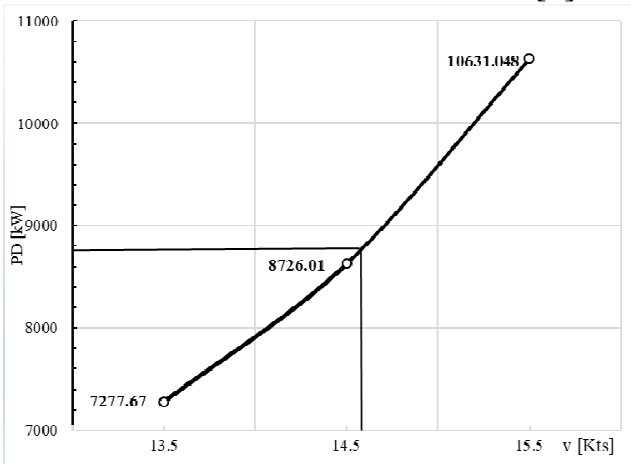

Fig. 6. Speed recalculated based on available propeller power and reference speed for

MAN B\&W S60ME-C8

Table 4. Calculation of the EEDI for MAN B\&W S60ME-C8 engine

\begin{tabular}{|c|c|c|}
\hline Parameters & Values & Units \\
\hline $\mathrm{P}_{\mathrm{ME}}$ & 8925.0 & {$[\mathrm{~kW}]$} \\
\hline $\mathrm{P}_{\mathrm{AE}}$ & 547.5 & {$[\mathrm{~kW}]$} \\
\hline$V_{\text {ref }}$ & 14.6 & [Knots] \\
\hline Attained EDDI & 4.63 & {$\left[\frac{g \mathrm{Co}_{2}}{\operatorname{tnm}}\right]$} \\
\hline \multicolumn{3}{|c|}{ Required EDDI } \\
\hline$x=0$ & 4.64 & {$\left[\frac{g \mathrm{CO}_{2}}{\operatorname{tnm}}\right]$} \\
\hline$x=10$ & 4.17 & {$\left[\frac{g \mathrm{Co}_{2}}{\operatorname{tnm}}\right]$} \\
\hline$x=20$ & 3.71 & {$\left[\frac{g \mathrm{CO}_{2}}{\operatorname{mn}}\right]$} \\
\hline$x=30$ & 3.25 & {$\left[\frac{g \mathrm{Co}_{2}}{\operatorname{tnm}}\right]$} \\
\hline
\end{tabular}

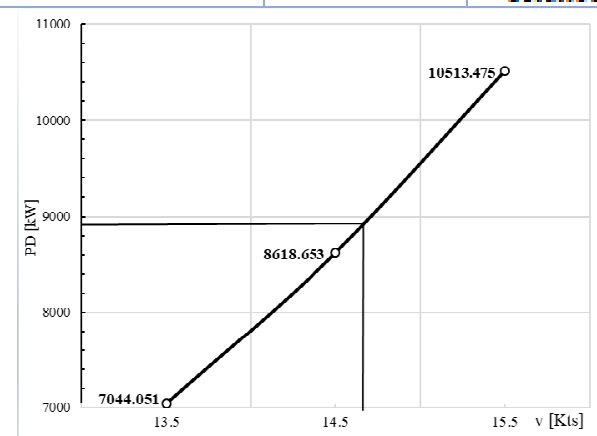

Fig. 7. Speed recalculated based on available propeller power and reference speed for MAN B\&W G50ME-C9 
Table 5. Calculation of the EEDI for MAN B\&W S60ME-C8 engine

\begin{tabular}{|c|c|c|}
\hline Parameters & Values & Units \\
\hline $\mathrm{P}_{\mathrm{ME}}$ & 9030.0 & {$[\mathrm{~kW}]$} \\
\hline$P_{\mathrm{AE}}$ & 551.0 & {$[\mathrm{~kW}]$} \\
\hline$V_{\text {ref }}$ & 14.7 & [Knots] \\
\hline Attained EDDI & 4.63 & {$\left[\frac{g \mathrm{CO}_{2}}{t m m}\right]$} \\
\hline \multicolumn{3}{|c|}{ Required EDDI } \\
\hline$x=0$ & 4.64 & {$\left[\frac{g \mathrm{CO}_{2}}{t w m}\right]$} \\
\hline$x=10$ & 4.17 & {$\left[\frac{g \mathrm{C}_{2}}{\mathrm{tmm}}\right]$} \\
\hline$x=20$ & 3.71 & {$\left[\frac{g \mathrm{CO}_{2}}{t m m}\right]$} \\
\hline$x=30$ & 3.25 & {$\left[\frac{g \mathrm{CO}_{2}}{\mathrm{tmm}}\right]$} \\
\hline
\end{tabular}

Referring to the two engines the value of the attained EEDI is the same and it is below the first reference line of Phase 0.

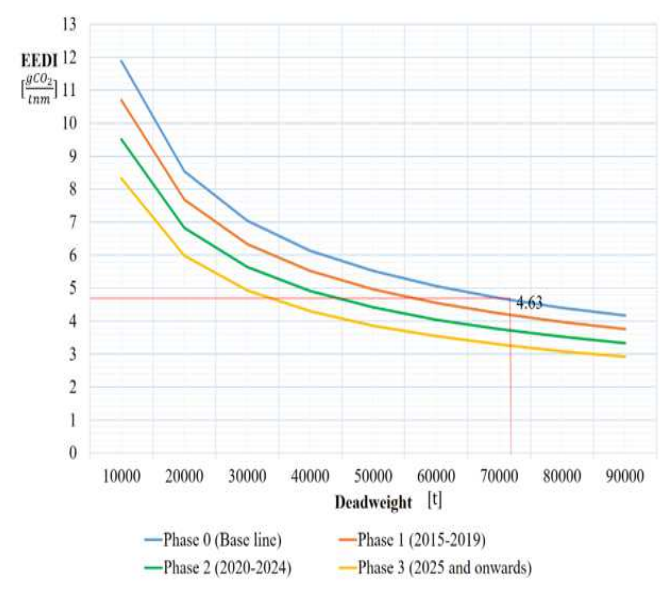

Fig. 8. Energy Efficiency Design Index using $D_{e}=0.395 \cdot 14.4+1.3$

\section{CONCLUDING REMARKS}

If the calculated EEDI are above the required values it become mandatory to find appropriate solutions to reduce GHG emissions. When the evaluations are carried out for a new ship there are still possibilities to carry out hydrodynamic tests or calculations which could lead to significant improvements mainly related to the reevaluation of ship's forms. There are also important resources to be considered using special energy saving devices.

The idea to reduce the speed, which is the simplest one, can't be an option as far as is practically a result of economic efficiency calculations and an important criterion for the ship owner.

The present study is focused on propulsion solutions from the main engine point of view and ways to evaluate the propeller diameters. On the other hand there are other ways to improve the efficiency like fuel efficiency such as waste heat generators, which do not have an impact on speed but on the auxiliary engines. Using fuels with low content $\mathrm{CO}_{2}$ or even 0 is another way to reduce the GHG emissions [6].

The present analysis underlines that the selection of an optimum combination propeller - engine is the result of a compromise that the designer has to take into account each solution having advantages and disadvantages. However, the results are clearly proving that some other solutions have to be considered specifically related to innovative ones. It is also important to observe that the analysis carried out for the bulk carrier, having a given geometry, can't comply with IMO requirements and such a design has to be consistently reconsidered.

\section{Acknowledgements}

The research was supported by the Research Centre of the Naval Architecture Faculty of "Dunărea de Jos" University of Galati.

The authors would like to express their gratitude for the support kindly offered by Associate Professor Ph.D. Mihaela Amorăriței from the Naval Architecture 
Faculty of "Dunărea de Jos" University of Galati, putting to our disposal valuable information and advices.

\section{REFERENCES}

[1]. IMO, „Low carbon shipping and air pollution control,"

Available:http://www.imo.org/en/MediaCent re/HotTopics/GHG/Pages/default.aspx

[2]. D. Obreja, "Teoria navei, Concepte și metode de analiză a performanțelor de navigație”, București: Editura Didactică și Pedagogică, 2005
[3]. IMO, Ship Energy Efficiency Regulations and Related Guidelines, London: IMO, 2016

[4]. B. C. B. R. X. M. D. R. Naya Olmer, Greenhouse Gas Emissions from Global Shipping, 2013-2015, The International Council on Clean Transportation, 2017

[5]. M. L. Hans Otto, Prediction of Resistance and Propulsion Power of Ships, University of Denmark, 2013

[6]. IMO, „EEDI - rational, safe and effective,” Available:http://www.imo.org/en/MediaCent re/HotTopics/GHG/Pages/EEDI.aspx.

Paper received on December 31th, 2018 